\title{
Modeling of the spatial distribution of the components for the ecosystem of the Novosibirsk reservoir
}

\author{
Aleksandr A. Tskhai ${ }^{1,2}$, Vladislav Yu. Ageikov ${ }^{1}$ and Aleksandr N. Semchukov ${ }^{1}$ \\ ${ }^{1}$ Institute for Water and Environmental Problems SB RAS, Barnaul, Russia \\ ${ }^{2}$ Polzunov Altai State Technical University, Barnaul, Russia
}

\begin{abstract}
The object of the study is the ecosystem of the largest in Western Siberia - the Novosibirsk reservoir. The aim of the study is forecast the response of hydrobiocenosis on the implementation of different methods for the aquatic ecosystem restoration. Novelty: structural-dynamics modeling of ecological processes based on the reproduction of biogeochemical cycles of limiting elements in the conditions of spatial heterogeneity for the reservoir is performed. A preliminary conclusion is formulating about the main role of autochthonous processes in the eutrophication of the Novosibirsk reservoir. A comparative assessment of the influence for three variants of washing the reservoir with a flood wave on the annual variability of the phytoplankton content and nitrate concentration in three characteristic parts of the Novosibirsk reservoir was carried out.
\end{abstract}

\section{Keywords}

Novosibirsk reservoir, ecosystem, eutrophication, restoration, spatially inhomogeneous, prediction, model.

\section{Introduction}

The Novosibirsk reservoir (NR) is the largest in Western Siberia. Trophic status of the NR (in the end of $20^{\text {th }}$ century) has attributed to the oligo-mesotrophic type [1]. The study of the ecosystem state for the NR in the last thirty years indicates the development of eutrophication in this water body: "... The largest recorded chlorophyll "a" concentrations (up to $45.5 \mathrm{mg} / \mathrm{m}^{3}$ ) corresponded to highly eutrophic water bodies. The occasional concentrations of chlorophyll "a" up to 298-316 $\mathrm{mg} / \mathrm{m}^{3}$ recorded during the so-called "water blooming" because of the local and short-term mass development of cyanoprokaryotes, correspond to the hypereutrophic level and serve as environmental risk factor for the fishery and recreational use of the reservoir, as well as for drinking water supply" [2]. Eutrophication is the excessive development of primary productivity processes, accompanied by the degradation of water communities, which, as a result, can lead to the impossibility of use a water body by inhabitants.

Therefore, today the question of measures to restore the ecosystem of the NR is relevant. World practice shows that the relevant measures are very expensive projects. For example, the cost of restoring Great Lakes ecosystems that have been eutrophied is estimating by the Federal

SDM-2021: All-Russian conference, August 24-27, 2021, Novosibirsk, Russia

$\bigoplus$ tskhai@iwep.ru (A. A. Tskhai)

(c) (1) ๑ 2021 Copyright for this paper by its authors. Use permitted under Creative Commons License Attribution 4.0 International (CC BY 4.0).

[eEUR Workshop Proceedings (CEUR-WS.org) 
Environmental Protection Agency (US) to be more than a billion dollars [3]. Therefore, the use of mathematical modeling to assess the environmental consequences of the rehabilitation of the NR has become an important issue when considering various ways to improve it.

A model "Biogen" of the biogeochemical transformation of the limiting elements nitrogen and phosphorus (for example, [4]) has used to assess the state of the reservoir ecosystem under study. Recently, a spatially inhomogeneous modification of this model has developed [5]. Using structural-dynamic modeling, the ecohydrological mechanism of unusual spatial distributions of phytoplankton in the NR has reproduced and evaluated [6].

The results of the application of the developed model approach for predicting the consequences of applying to the object under study known in the world practice $[7,8]$ measures for the improvement of aquatic ecosystems are presenting here.

\section{Materials and methods}

A comprehensive study of the NR conducted in 1981/1982 yielded a body of data allowing for a tentative model description of the processes in the reservoir ecosystem [1]. The scenario of annual dynamics of component concentrations in the head section of the reservoir (the Kamen'-na-Obi) was selected based on actual concentrations of mineral forms of $\mathrm{N}\left(\mathrm{NH}_{4}, \mathrm{NO}_{2}\right.$, $\mathrm{NO}_{3}$ ), $\mathrm{P}, \mathrm{O}_{2}$, chlorophyl "a", zooplankton, phytoplankton, organic matter and detritus with the use of empirical relationships [4].

The box approximation [5] is used for simulation of spatial heterogeneity of environmental processes. To do that, ten areas of the reservoir divided into three layers by depth (30 boxes in total) are used.

Seven areas are located along the main stream, two - in shallow waters near the left bank, and one - in the Berd Bay (Figure 1). If depth exceeds $2 \mathrm{~m}$, the upper and lower layers are

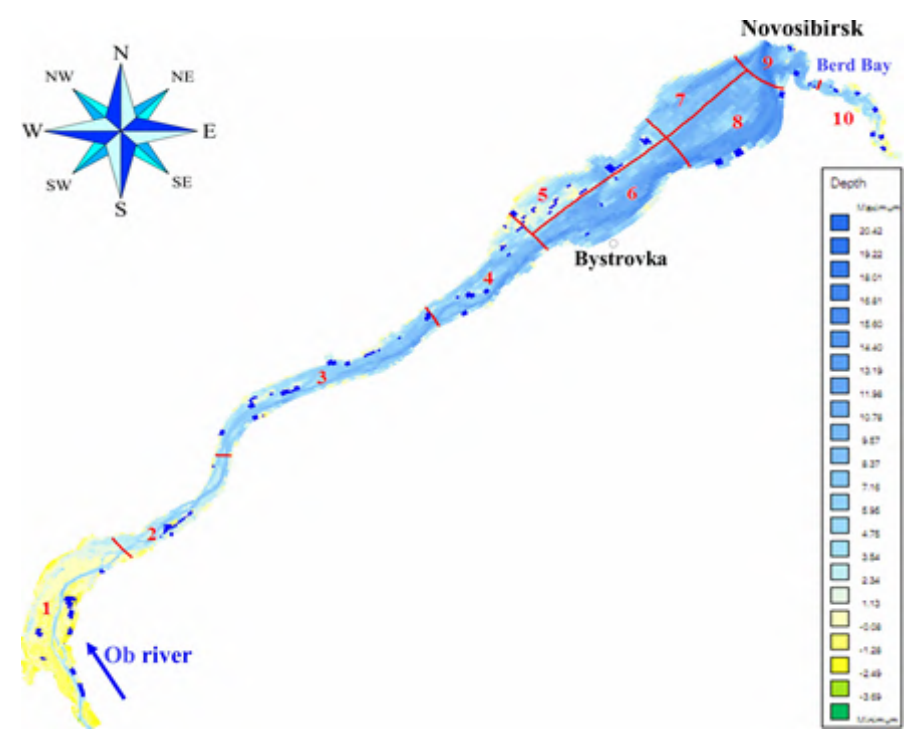

Figure 1: The Novosibirsk reservoir areas. 
assuming to be of $1 \mathrm{~m}$ thick. The bottom layer is absent if depth is less than $1 \mathrm{~m}$. Under ice conditions, depth $\mathrm{H}$ is the distance from the ice low boundary to the bottom.

To simulate environmental processes based on solving three-dimensional hydrothermal and box's biogeochemical tasks, the variability of the spatial-temporal structure of water flows, matters and temperatures for the conditions of 1981 was reproduced [5].

The hydrothermal block of the "Biogen" model has defined using the following initial information as the average daily parameters of each box. The list of data is as follows: water temperature, volume, metric area, length, width and height of the box; the metric area of contact with the bottom; the metric area of the ice-free surface; the thickness of the ice; the distance from the box to the water surface or the lower surface of the ice; positive and negative components of the water discharges into this box from others.

Transformation and dynamics of nine $C_{i}$ variables (Figure 2) are simulating to reproduce the processes of biogeochemical transformation of nitrogen and phosphorus compounds as well as oxygen regime in the surface and intermediate boxes. These variables relate to a water column, where $Z O$ - zooplankton biomass, $F$ - phytoplankton biomass, $N H 4, N O 2, N O 3$ - mineral forms of N, $D$ - suspended substances, $C$ - dissolved organic substances, $I-$ mineral $\mathrm{P}$ and $O 2-$ oxygen.

Extra six variables are adding to do calculations for bottom boxes. $C B$ is organic matter (OM) involved in metabolic processes. Interstitial forms of phosphorus and nitrogen are $P B$ and $N B$, respectively. Forms of phosphorus and nitrogen sorbed at solid phase of bottom sediments are designating as $P S$ and $N S$. Passive $\mathrm{OM}$ in the bottom sediment are marked as variable $C N$.

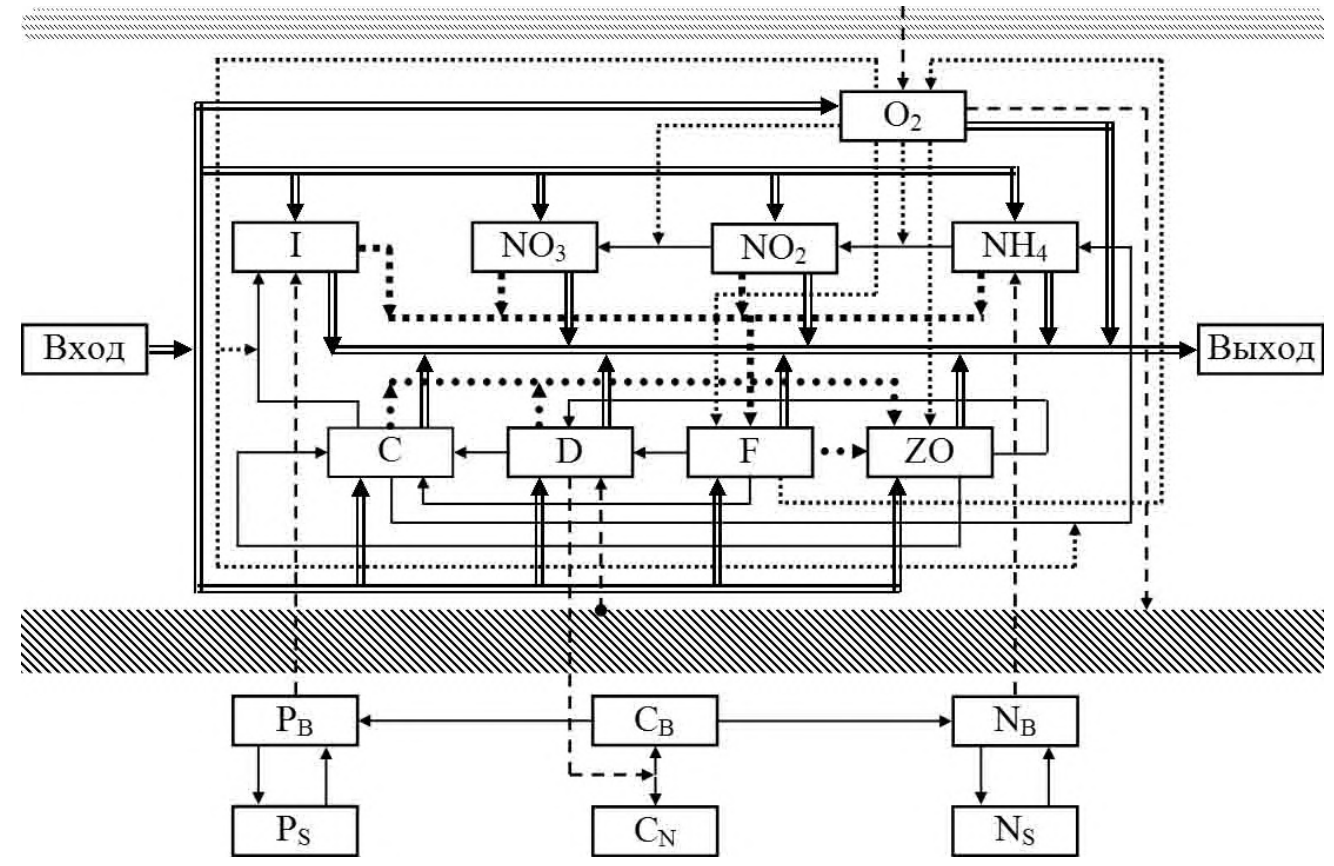

Figure 2: A scheme of biochemical components transformation in the aquatic ecosystem according to the model "Biogen". 
Equations of the "Biogen" model for description of the $i$-th component transformation into the $j$-th box are as follows:

$$
\frac{d\left(C_{i}^{j} \cdot W_{j}\right)}{d t}=W_{j} \cdot R_{i}^{j}+\sum_{k} Q_{k j} \cdot C_{i}^{k}-\sum_{q} Q_{j q} C_{i}^{j}+J_{i}^{j} \cdot \Omega_{j}+G_{i}^{j} L_{j},
$$

where $i=Z O, F, N H 4, N O 2, N O 3, D, C, I, O 2 ; C_{i}^{j}$ - the concentration of the $i$-th component in the $j$-th box; $W_{j}$ - the volume of the $j$-th box; $t$ - the time; $R_{i}^{k}$ - the rate of biochemical transformation of $C_{i}$ in the $k$-th box; $Q_{k j}$ - the water discharged from the $k$-th box to the $j$-th box; $J_{i}^{j}$ - the mass flow of the $i$-th component through the interfacial surface into the $j$-th box; $\Omega_{j}$ - the metric area of the interfacial surface of the $j$-th box; $G_{i}^{j}$ - the lateral load of the $i$-th component in the $j$-th box; $L_{j}$ - the length of the $j$-th box.

In the intermediate and bottom boxes, the lateral load $G_{i}^{j}$ is assumed to be zero. The runoff from the reservoir banks makes up less than $6 \%$ of the river's water flow [1]. Special calculations for $\mathrm{N}$ and $\mathrm{P}$ compounds arrived from the reservoir bank ( $0-12 \%$ of the river's biogenic load) do not reveal a significant difference in annual variability of the simulated components.

Terms and values of internal parameters of the "Biogen" model are given in [4]. Unknown parameters of the "Biogen" model [4] were found within the intervals of typical values by minimizing $\mathrm{Cr}$ - the Theil's statistical criterion [9] for components of the aquatic ecosystem:

$$
\mathrm{Cr}=\frac{\sqrt{\sum_{i=1}^{n}\left(X_{i}-Y_{i}\right)^{2}}}{\sqrt{\sum_{i=1}^{n} X_{i}^{2}}+\sqrt{\sum_{i=1}^{n} Y_{i}^{2}}},
$$

where $n$ is the number of observations, and $X_{i}$ and $Y_{i}$ are the simulated and observed values of substance concentrations, respectively. This model is used as a basis for monitoring the aquatic ecosystems of the Ob river [10].

In the current model approaches (the review is given, for example, in [11]), the dynamics of ecosystems are considered, as a rule, within the framework of the equilibrium approximation, which makes it impossible to characterize new for the hydrobiocenosis, significantly nonequilibrium cases, such as degradation or restoration for the state of the aquatic ecosystem. Tools which allow to flexibly adjust the internal structure of the ecosystem model are needed. To take into account intensive impacts on the ecosystem, it is necessary. Such changes lead the hydrobiocenosis out of the circle of past equilibrium states.

In order to construct adaptive models, one should set a criterion for choosing from a set of trajectories for ecosystem behavior under non-equilibrium conditions. The structural-dynamic models (SDM) that appeared at the end of the 20th century in the search for a possible response of an ecosystem to a violation of its stability use the assumption of non-equilibrium thermodynamics. It is about the preference for a development trajectory that corresponds to the possible maximum order of a living system in specific conditions [7].

The first steps have been taken on this path only if time changes in the simulated ecosystem are taken into account, which, in particular, did not allowed to take into account the role of 
spatial mechanisms that determine the intra-water mass and energy flows of substances that occur in real ecosystems (for example, [8]).

In this regard, in this study, the development of a structural-dynamic approach aimed at taking into account spatial factors was carried out. This allowed us to perform a model assessment of the impact of the possible use of methods for restoring water ecosystems on the spatial variability of the ecosystem components of the NR.

\section{Results and discussion}

By modeling the biogeochemical cycles of transformation of biogenic elements, the features of the hydrochemical and hydrobiological regimes of the NR for the conditions of 1981 are reproduced. The study uses the results of parameterization of the "Biogen" model in the zerodimensional approximation [4]. The simultaneous solution (in 30 boxes) of zero-dimensional tasks with account of heat, water and mass exchange allowed us to estimate the spatially inhomogeneous dynamics of the components of the water ecosystem of the NR.

To simulate the ecosystem restoration of the NR, the results of the application of the most well-known method of managing the aquatic ecosystem by reducing the biogenic load from the catchment area are presented in a scenario manner. This method consists in carrying out a complex of water protection measures, which would reduce the pollution of the studied water body.

Theoretically, when implementing effective measures in the catchment area, it is possible to reduce the content of nitrogen and phosphorus compounds in the river to $80 \%$ or even $60 \%$ of the actual observed concentrations. How would this affect the state of the ecosystem of the NR? To answer this question, special simulation was carried out with the variation of the biogenic load on the NR, which allowed us to obtain the spatial and temporal distribution of pollution in the water areas. The difference between the content of pollutants in the case of a decrease in the biogenic load is reduced compared to the reality, but only by a few percent. This result suggests that autochthonous processes play a major role in eutrophication in the NR. As noted above, the costs of limiting the biogenic load are very high.

Another way to restore water quality: the maximum flushing of a reservoir by a flood wave is used in the world (for example, [8]). To simulate the response of the ecosystem of the NR under consideration, in addition to the real one, the first and second scenarios for managing the operation mode of the hydroelectric power station were formed (Figure 3).

The meaning of the first scenario option was to pass the maximum volume of water through the dam during the flood, but so that during further operation it would be possible to navigate river vessels through the NR toward middle part of the Ob river. In the second scenario, and this restriction is removed, the maximum water level during the filling phase is such that during the subsequent low-water periods there is enough water for the water supply of settlements only. The modeling result of the ecosystem responses was shown in Figures 4-9.

The implementation of such scenario options may have a number of other water management and environmental consequences, which should be taken into account when planning the actual operation of the reservoir. In this study, only one aspect was considered: how will a scenario-defined flood wave wash affect the intra-annual dynamics of phytoplankton content 


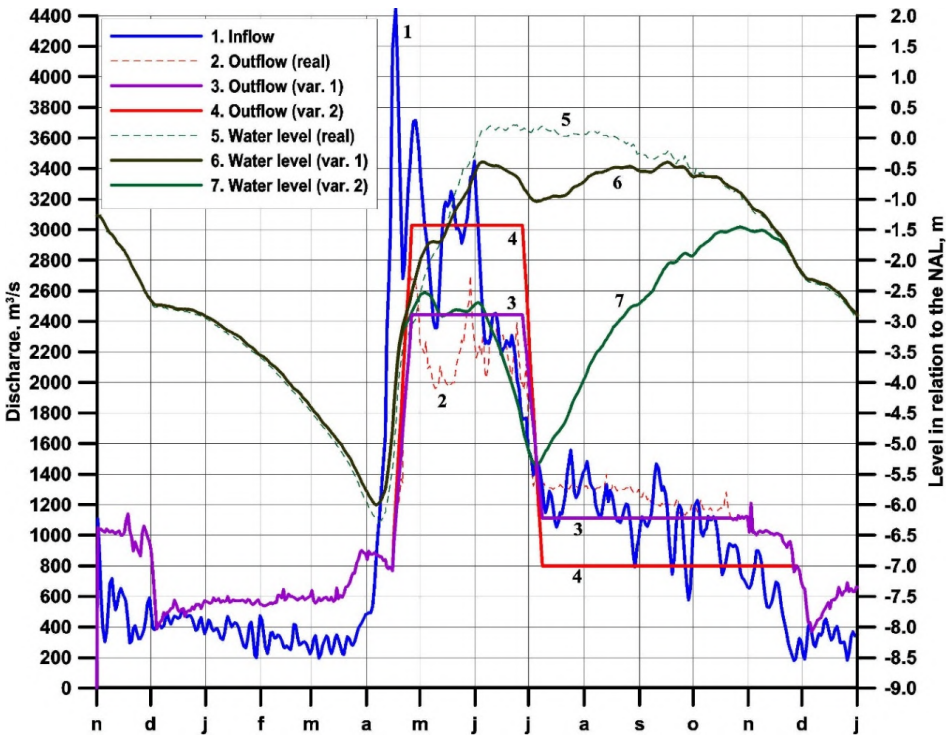

Figure 3: Inflow and outflows, levels of the Novosibirsk reservoir from November 1980 until January 1982 for three variants: real; intermediate and maximal washout.

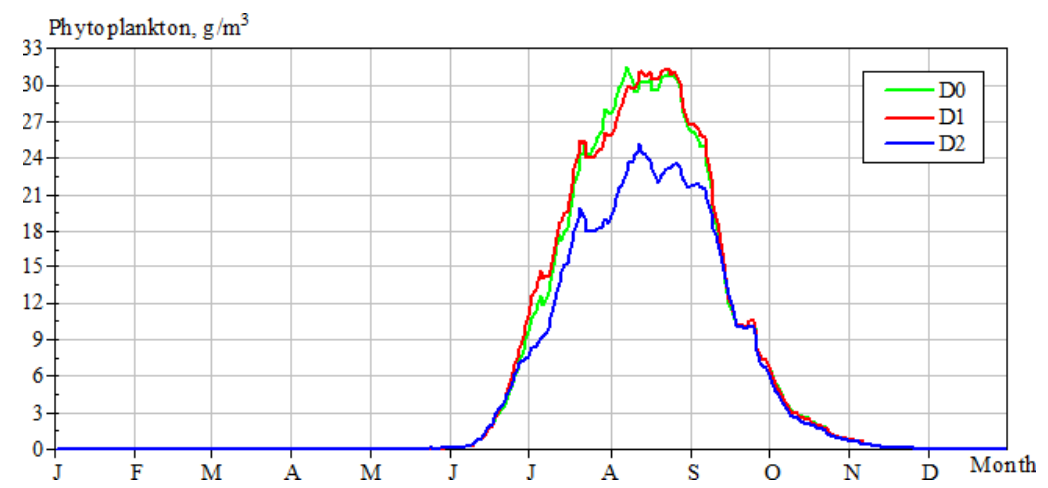

Figure 4: Annual variability of phytoplankton content in the $6^{\text {th }}$ area for three regimes of the Novosibirsk reservoir exploitations in 1981.

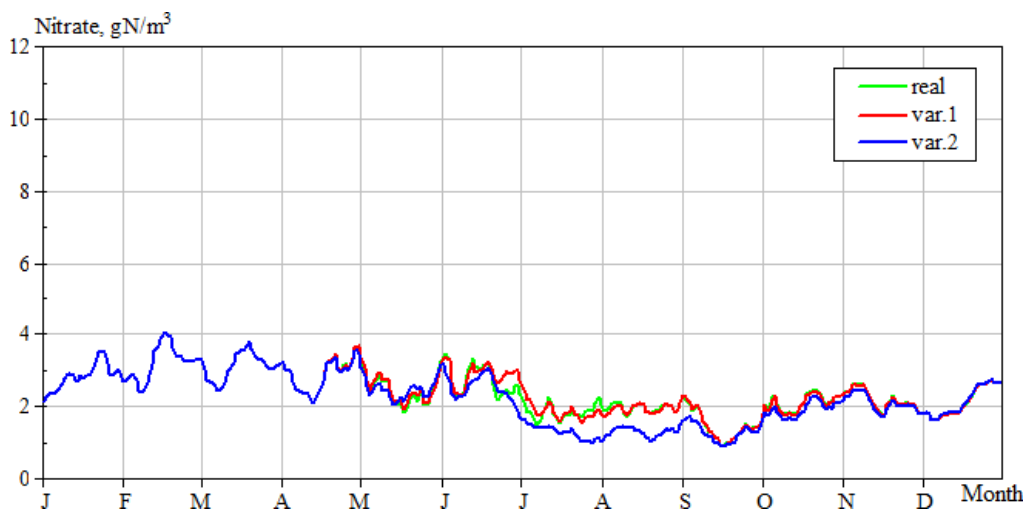

Figure 5: Annual variability of nitrate concentrations in the $6^{\text {th }}$ area for three regimes of the Novosibirsk reservoir exploitations in 1981. 


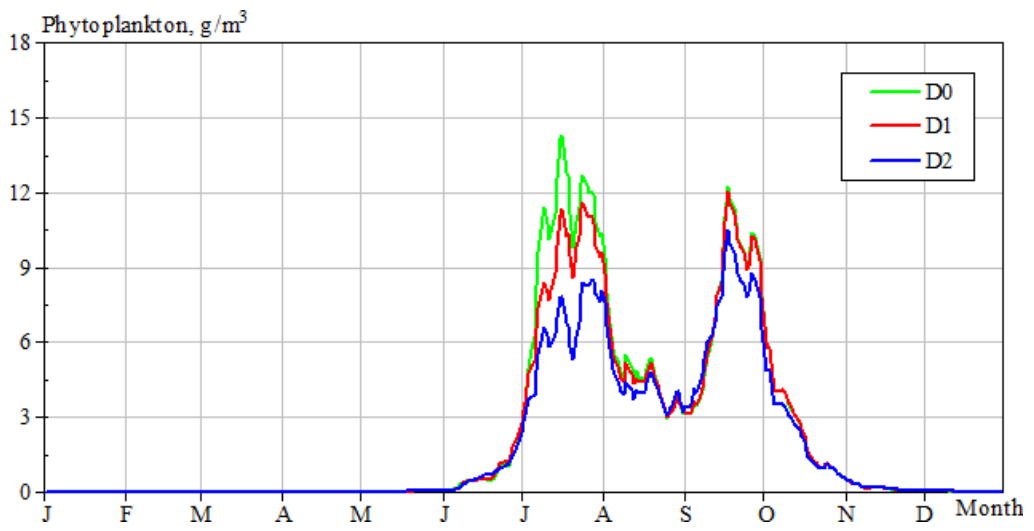

Figure 6: Annual variability of phytoplankton content in the $9^{\text {th }}$ area for three regimes of the Novosibirsk reservoir exploitations in 1981.

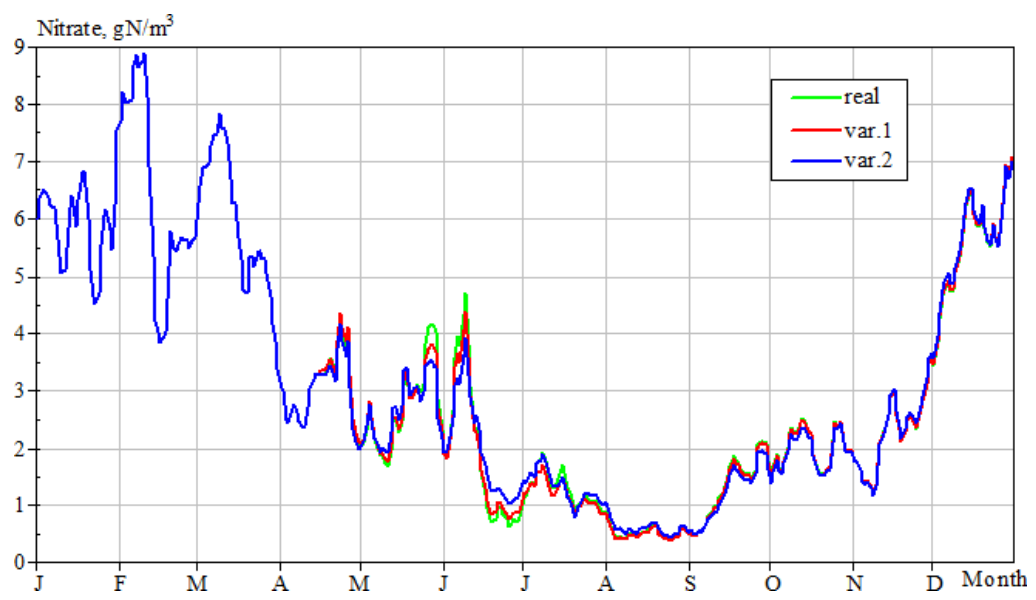

Figure 7: Annual variability of nitrate concentration in the $9^{\text {th }}$ area for three regimes of the Novosibirsk reservoir exploitations in 1981.

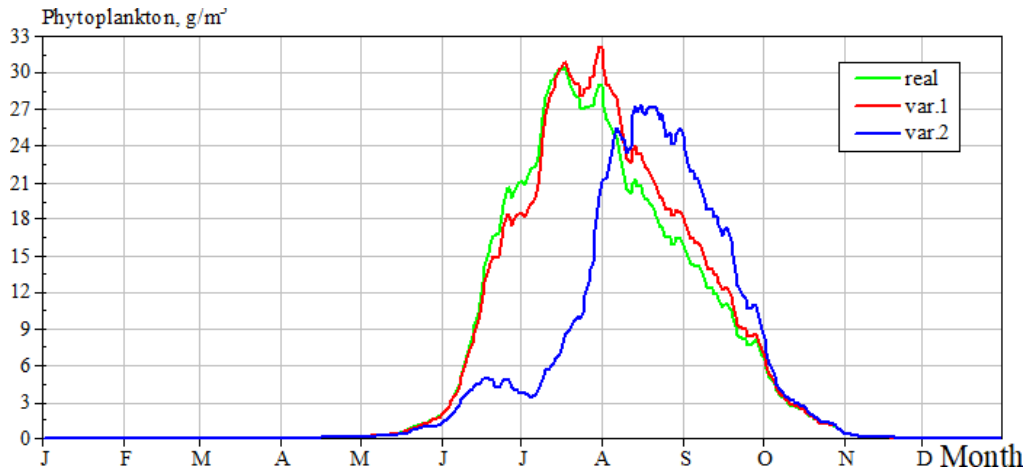

Figure 8: Annual variability of phytoplankton content in the $10^{\text {th }}$ area for three regimes of the Novosibirsk reservoir exploitations in 1981. 


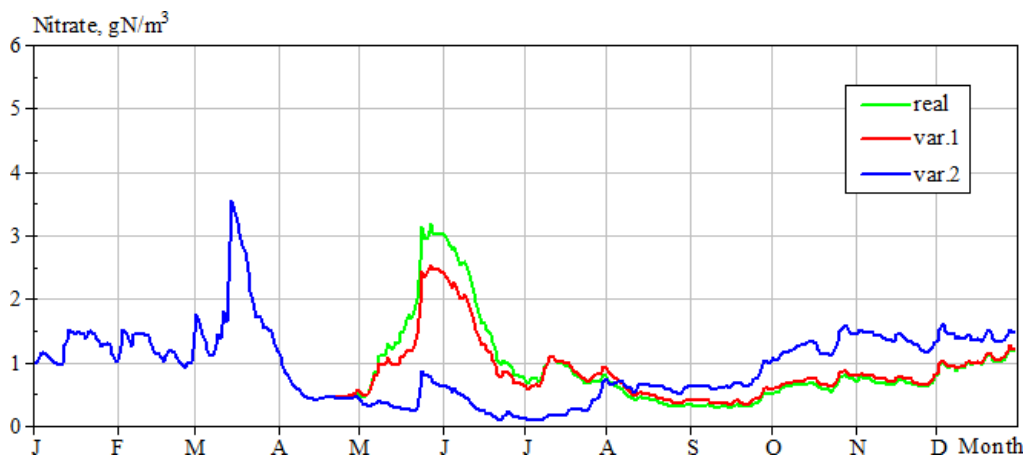

Figure 9: Annual variability of nitrate concentration in the $10^{\text {th }}$ area for three regimes of the Novosibirsk reservoir exploitations in 1981.

and other controlled water quality indicators. In addition, the entire array of information that is obtained as a result of simulation, but due to the limited volume is not given in this publication, should be analyzed.

The results of the corresponding calculations of the content of phytoplankton and nitrates in the case of the three above-described modes of operation of the hydroelectric power station for the surface layers of three water areas of the main part of the NR and the Berd Bay are presented. The first of them was considered the $6^{\text {th }}$ water area, the most susceptible to eutrophication (Figures 4 and 5). Secondly, the $9^{\text {th }}$ water area, which provides water for the Novosibirsk water intake, is here (Figures 6 and 7). Finally, the Berd Bay is of particular importance as a source of water for the Berd water intake (Figures 8 and 9).

An increase in the intensity of reservoir flushing due to a flood wave would lead to a noticeable decrease in the maximum level of phytoplankton content in the surface layers of the water areas of the main part of the NR (by one and a half to two times).

The implementation of the second scenario does not differ much from the real version of the temporal picture of phytoplankton in the Byrd Bay. However, the maximum washing (the third scenario) would lead to a temporary shift of the peak of the algae content by almost a month in the $10^{\text {th }}$ water area. This can be understood by taking into account the peculiarities of the water exchange of the Berd Bay with the near-dam part of the NR in the summer low water.

The maximum permissible concentration of nitrates in the Russian Federation for water bodies of fisheries significance is $9.1 \mathrm{gN} / \mathrm{m}^{3}$. The considered regimes would not cause a significant change in the content of nitrate pollution in the water areas of the main part in the HR (Figures 5 and 7). At the same time, in the $10^{\text {th }}$ water area from the end of May, the nitrate content in the case of the third scenario would significantly (by 2-3 times) decrease compared to the first and second, and, starting from mid of August - until the end of the year, on the contrary, it would slightly increase. The explanation is in the corresponding alternation of periods for activity of phytoplankton.

The results of the corresponding calculations of the content of phytoplankton and nitrates in the case of the three above-described hydroelectric power station operating modes for the surface layers of two water areas. First of them, the $6^{\text {th }}$ area most susceptible to eutrophication was considered (Figure 4). Secondly, the $9^{\text {th }}$ area is which water outflow enters for the Novosibirsk 
water intake from (Figure 5). It can be seen that an increase in the flushing of the reservoir due to the flood wave would lead to a noticeable decrease in the maximum level of phytoplankton content in the surface layers of the water areas of the NR to one and a half to two times. The maximum permissible concentration of nitrates in the Russian Federation for water objects of fishery significance is $9.1 \mathrm{~g} / \mathrm{m}^{3}$. Considered modes would not have caused a essentially increase in the content of nitrate contamination (Figures 6 and 7).

\section{Conclusion}

Model estimates of the impact of the use of different methods of restoring the aquatic ecosystem on the spatial distribution of ecosystem components are obtained, including for the case of three variants of the HB operation mode during a flood. The result of calculations for the surface layers of the main part of the Novosibirsk reservoir $\left(6^{\text {th }}, 9^{\text {th }}\right)$ and the Berd Bay $\left(10^{\text {th }}\right)$ water areas of phytoplankton content and types of pollution is given on the example of nitrates for the case of three modes of annual operation of the NR. The results of preliminary scenario calculations show that the use of reservoir flushing during a flood would significantly affect the level of phytoplankton content in the surface layers of the selected water areas for comparison. A preliminary conclusion is formulated about the main role of autochthonous processes in the eutrophication of the Novosibirsk reservoir.

\section{Acknowledgments}

The study carried out within the Research Programs of the Institute for Water and Environmental Problems SB RAS and the Polzunov Altai State Technical University; was funded by the Russian Foundation for Basic Research and the government of Altai Krai, the Russian Federation (grant No. 18-41-220002).

\section{References}

[1] Podlipskii Yu.I., Chaikovskaya T.S. Comprehensive studies of the Novosibirsk reservoir. Moscow: Gidrometeoizdat, 1985.

[2] Vasiliev O.F. Long-term dynamics of water-ecological regime of the Novosibirsk reservoir. Novosibirsk: SB RAS Publ. House, 2014.

[3] The great lakes restoration initiative: Background and issues. Available at: https://www. everycrsreport.com/reports/R43249.html\#_Toc370914293.

[4] Tskhai A.A., Ageikov V.Yu. Disturbance of sustainability of the reservoir ecosystem: A model approach for assessing and forecasting the long-term process of eutrophication // Journal of Sustainable Development of Energy, Water and Environment Systems. 2021. Vol. 9. Is. 1. 1080327. DOI:10.13044/j.sdewes.d8.0327.

[5] Tskhai A.A., Ageikov V.Yu., Semchukov A.N. Modelling of transformation features for nitrogen and phosphorous compounds in the conditions of the Novosibirsk reservoir // Water Sector of Russia. 2020. Vol. 6. P. 87-102. DOI:10.35567/1999-4508-2020-6-5. 
[6] Tskhai A., Ageikov V., Semchukov A. Hydrological paradoxes of phytoplankton distribution in the Novosibirsk reservoir // EGU General Assembly 2021. Online, 19-30 Apr 2021, EGU21-287. DOI:10.5194/egusphere-egu21-287.

[7] Jørgensen S.E. Lake management. Oxford: Pergamon Press, 1980.

[8] Kong X.-Z., Jørgensen S.E., He W., Qin N., Xu F.-L. Predicting the restoration effects by a structural dynamic approach in Lake Chaohu, China // Ecological Modelling. 2013. Vol. 266. P. 73-85.

[9] Theil H. Applied economic forecasting. North-Holland: Amsterdam, 1971.

[10] Tskhai A., Puzanov A. Kovalevskaya N., Kirillov V. New approach to aquatic ecosystems monitoring for the Ob-river // Proceedings of the International Association of Hydrological Sciences. 2020. Vol. 383. P. 375-379. DOI:10.5194/piahs-383-375-2020.

[11] Vinçon-Leite B., Casenave C. Modelling eutrophication in lake ecosystems: A review // Science of Total Environment. 2019. Vol. 651. Pt 2. P. 2985-3001. DOI:10.1016/j.scitotenv.2018.09.320. 